\title{
RESEARCH ON COMBUSTION MODE OF METHANOL MICRO-RECIPROCAING PISTON INTERNAL COMBUSTION ENGINE
}

\author{
TANG Gang Zhi " ${ }^{\text {, }}$ WANG Shuai Bin ${ }^{1}$, ZHANG Li ${ }^{2}$, SHANG Hui Chao ${ }^{2}$ \\ ${ }^{1}$ College of Mechatronics \& Automotive Engineering, Chongqing Jiaotong University, \\ NO 66, Xuefu Rd, Nan'an Dist, Chongqing City, 400074, China \\ ${ }^{2}$ College of Automotive Engineering, Chongqing University, Chongqing, 400044, China
} Email: tanggz1980@163.com

\begin{abstract}
Constrained by the micro-space structure, it is proposed to use platinum wire incandescent ignition combustion mode to achieve the operation of internal combustion engine. However, the combustion test of the platinum wire incandescent ignition in miniature piston internal combustion engine shows: the combustion mode of micro-space platinum wire incandescent ignition has a poor combustion characteristic, low heat release rate, long combustion duration, and low combustion pressure. Therefore, a homogenous charge compression ignition mode is proposed to realize the operation of miniature internal combustion engine. However, it is found that the compression combustion cannot be come true in the cold start-up state of the micro engine. And the compression combustion in the first cycle was realized by the way of increasing the temperature of the cylinder block and platinum wire appropriately. The results show that: The maximum heat release rate is obviously improved and the combustion duration shortened by $28.6{ }^{\circ} \mathrm{CA}$, and pmi increased by $76 \%$.

So, a novel hybrid combustion mode of in-cylinder compression combustion supported by the platinum wire incandescent ignition is put forward, through the way of adjusting the temperature of platinum wire, and this combustion mode is regarded as the ideal combustion mode of micro reciprocating piston internal combustion engine.
\end{abstract}

Keywords: micro-energy power systems; combustion diagnosis; combustion model; methanol

\section{INTRODUCTION}

Micro-energy power systems can achieve ultra-high energy density power output at micro / intermediate scale [1]. Its representative research includes micro-turbine engines, micro-triangular rotor Wankel engines, miniature free piston engines, micro-steam turbines and micro Stirling engines as well as micro fuel cell systems, micro-thermoelectric systems and micro-thermal photovoltaic systems [2-5].

From the perspectives of energy density and conversion efficiency, the gas power cycle micro heat engine of the liquid hydrocarbon fuel has the potential to compete with the LiSO2 battery system [6-9] (the lower calorific value of hydrocarbon fuel can reach $105, \mathrm{~kJ} / \mathrm{kg}$ level, while the LiSO2 battery's energy density was only $102 \mathrm{~kJ} / \mathrm{kg}$ magnitude). Among them, the micro-reciprocating piston internal combustion engine may become a practical micro-energy power system because of its advantages such as simple structure [10-11].

However, the study on micro space combustion shows that the micro size effects such as high surface-volume ratio and short residence time lead to the difficulty of combustion in micro space and deteriorate the incomplete combustion, miss-fire and other abnormal combustion phenomena [12-13]. Constrained by the micro-space structure, the traditional spark ignition cannot be used in micro reciprocating piston type internal combustion engine. It is found that the fuel utilization rate is very low in the thermal wire ignition mode because of the limitation of the size of micro-combustion engine. In order to realize the homogenous charge compression ignition in micro-combustion engines, it is necessary to afford conditions which are difficult to control, such as sufficiently temperatures and active elements' catalytic action. Therefore, further analysis on different combustion modes of micro-combustion engines to develop new efficient and fast micro-space transient combustion modes is meaningful in the development of micro reciprocating piston internal combustion engine [14].

In view of this, a combustion test platform is established for the miniature reciprocating piston internal combustion engine to test the basic combustion characteristics of micro combustion engine. Furthermore, a novel combustion mode that is suitable for rapid and efficient combustion in micro-space is explored. This study contributes to the development of the ultra-high energy density power system of the miniature piston internal combustion engine.

\section{DIAGNOSIS OF PLATINUM WIRE INCANDESCENT IGNITION COMBUSTION MODE}

A combustion test platform for a miniature reciprocating piston internal combustion engine was constructed, as shown in figure 1 . The test system was driven by the motor, and the speed of the motor was adjusted by the transducer. The hysteresis brake was used as an adjustable load device to absorb the output torque of 
the engine and the motor. Kistler6052B quartz pressure sensor was adopted to collect the combustion pressure signal in the micro-piston internal combustion engine. The charge signal output by the piezoelectric sensor was converted into voltage signal by 5011B charge amplifier. The data was analyzed by DEWE2010 combustion analyzer. At the same time, the AVL365X angle instrument collects the crank angle signal, the sampling resolution was set to be $0.2^{\circ} \mathrm{CA}$. The test condition was full load at $6000 \mathrm{r} / \mathrm{min}$.

The basic parameters of the micro-piston internal combustion engine are as follows: the cylinder bore was $11.25 \mathrm{~mm}$, the stroke was $10 \mathrm{~mm}$, the compression ratio was 8 . The fuels are mixture of methanol, nitromethane (with
$15 \%$ volume fraction) and castor oil. Restrained by the micro-space structure, traditional spark ignition mode cannot be applied.

In order to evaluate the combustion characteristic of the platinum wire incandescent ignition combustion mode in a miniature piston internal combustion engine, it is compared with the combustion characteristics of a variety of conventional-size engines. Three different conventional-size engines are selected for the combustion diagnosis, which are labeled as 154FMI, 157FMI and 165FMI respectively. At the same time, the micro piston type internal combustion engine is labeled as ME. The basic parameters of the engine are shown in Table 1 . The test speed is $6000 \mathrm{r} / \mathrm{min}$.
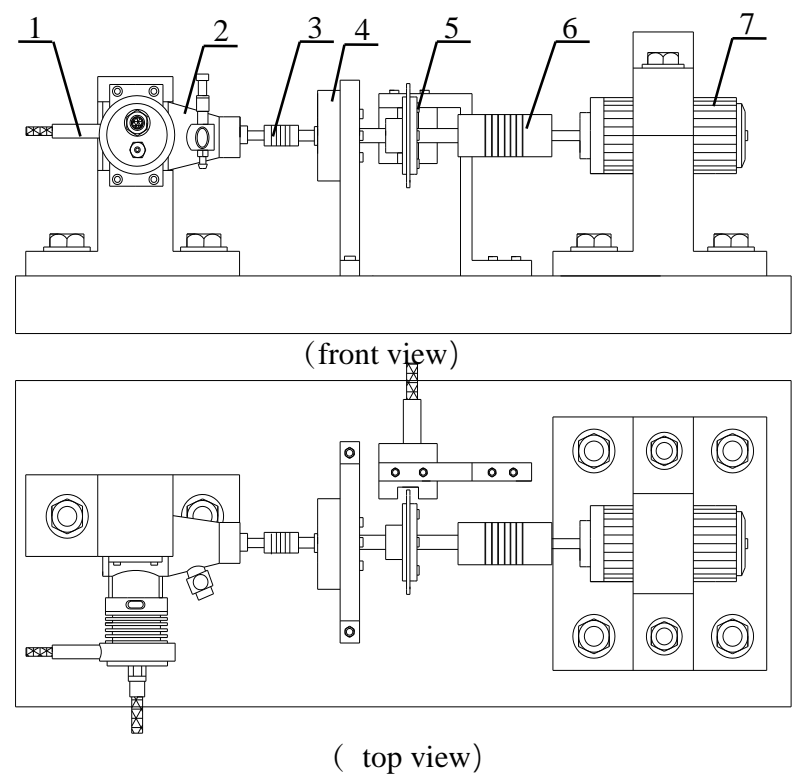

(a) Experimental platform

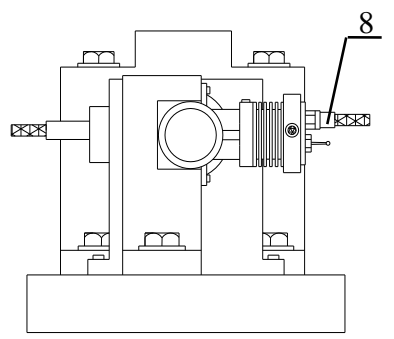

(left view)

1 - temperature sensor

2 - micro engine

3 - rigid coupling

4-Hysteresis brake

5 - angle encoder

6 - elastic coupling

7 -motor

8- pressure sensor
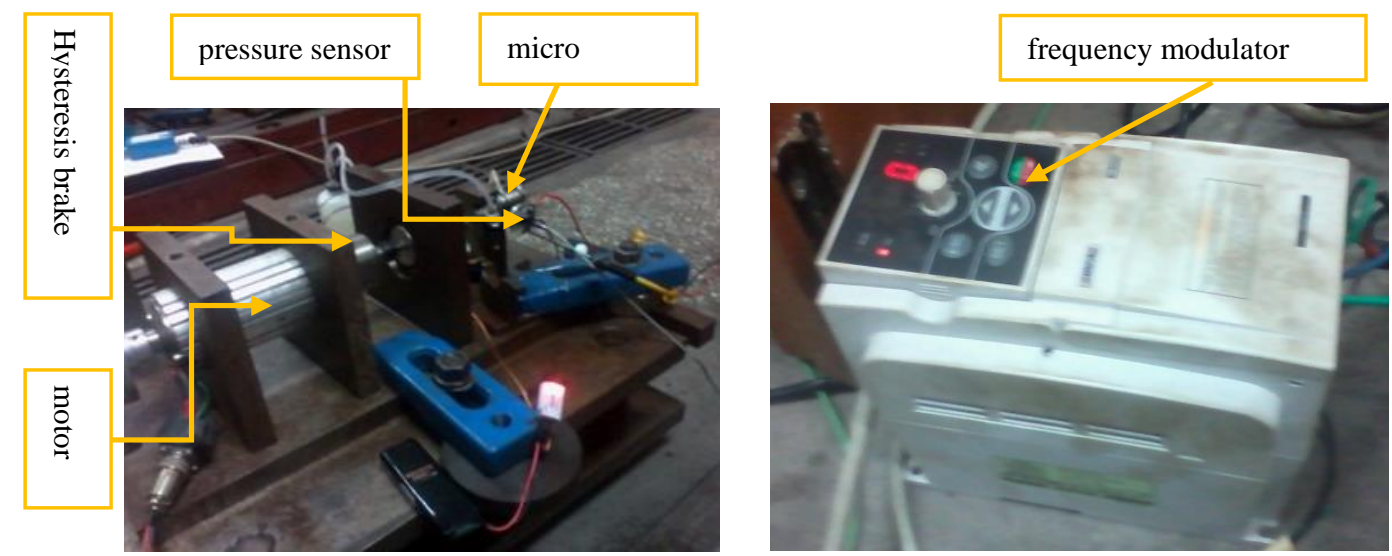

(b)Experimental installation

Fig.1 Experimental platform of the micro internal combustion engine

Tab.1 Engine parameters

\begin{tabular}{ccccc}
\hline parameter/units & ME & 154FMI & 157FMI & 165FMI \\
\hline Cylinder bore/mm & 11.25 & 54 & 58.5 & 65.5 \\
stroke/mm & 10 & 54 & 55.5 & 66.2 \\
Compression ratio & 8 & 10 & 9.6 & 9.2 \\
displacement/L & 0.001 & 0.125 & 0.15 & 0.225 \\
\hline
\end{tabular}


The combustion diagnosis of the conventional size engine adopts the Kistler 6052B pressure sensor to collect the pressure signal in the cylinder and convert the charge signal output by the piezoelectric sensor into a voltage signal through the 5011B charge amplifier. The DEWE-2010 combustion analyzer performs data processing. At the same time, the crank angle signal is collected by the Kistler 2613B crankshaft angle signal generator, sampling resolution is set to be $0.2^{\circ} \mathrm{CA}$.

Figure 2 shows the comparison of the cylinder pressure and the instantaneous heat release rate between the micro piston internal combustion engine and the conventional size engine. Table 2 is the combustion characteristic parameters of different engines. It can be seen from the figure 2 that the in-cylinder combustion characteristics of the micro

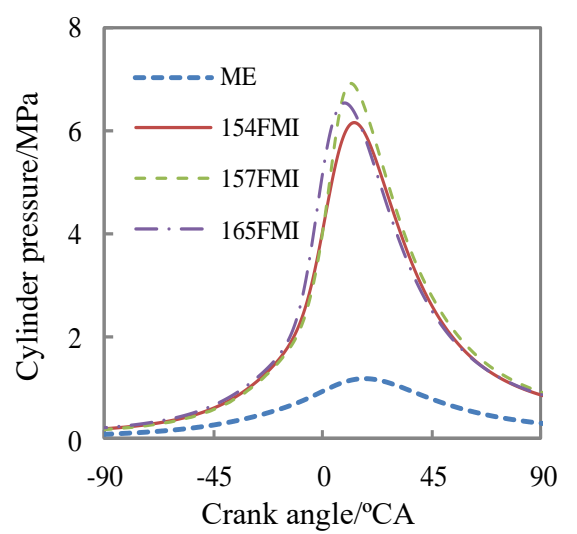

(a) cylinder pressure piston internal combustion engine are poor, the combustion pressure and the heat release rate are very low. The maximum combustion pressure is only $1.17 \mathrm{MPa}$, as shown in Table 2, which is much lower than the pressure (6 to 7 $\mathrm{MPa}$ ) of the conventional size engine. The crank angle corresponding to the maximum pressure is $17.4^{\circ} \mathrm{CA}$ after the top dead center, which is $5 \sim 9^{\circ} \mathrm{CA}$ later than the conventional engines. The lower combustion pressure and the delay of the crank angle corresponding to the maximum pressure reduce the expansion ratio of the engine and the thermal efficiency of the cycle. It is tested that the mean indicated pressure pmi is much lower than that of the conventional engines, with only $0.27 \mathrm{MPa}$, about $20 \%$ of the latter.

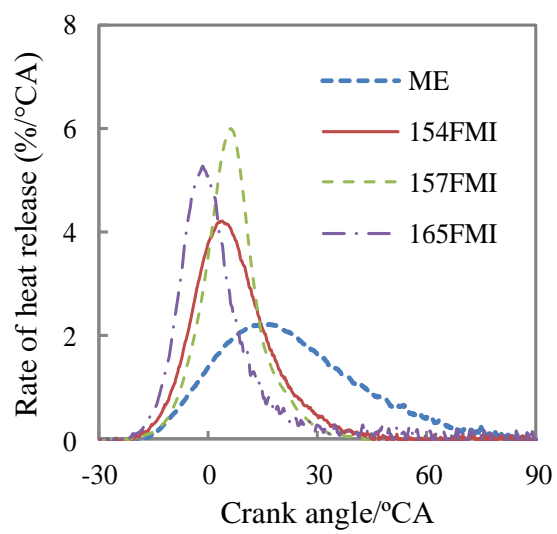

(b) Rate of heat release

Fig. 2 comparison of cylinder pressure and rate of heat release

Table 2 Combustion characteristic of different engines

\begin{tabular}{cccccccc}
\hline \multirow{2}{*}{ model } & $\begin{array}{c}p_{\max } \\
/ \mathrm{MPa}\end{array}$ & $\begin{array}{c}\mathrm{A} p_{\max } \\
/{ }^{\circ} \mathrm{CA}\end{array}$ & $\begin{array}{c}p_{\text {mi }} \\
/ \mathrm{MPa}\end{array}$ & $\begin{array}{c}\mathrm{CA} 05 \\
/{ }^{\circ} \mathrm{CA}\end{array}$ & $\begin{array}{c}\mathrm{CA} 10 \\
/{ }^{\circ} \mathrm{CA}\end{array}$ & $\begin{array}{c}\mathrm{CA} 50 \\
/{ }^{\circ} \mathrm{CA}\end{array}$ & $\begin{array}{c}\mathrm{CA} 90 \\
/{ }^{\circ} \mathrm{CA}\end{array}$ \\
\hline $\mathrm{ME}$ & 1.17 & 17.4 & 0.27 & -3.3 & 0.7 & 20.6 & 49.8 \\
154FMI & 6.24 & 12.8 & 1.22 & -8.9 & -5.8 & 5.5 & 21.5 \\
157FMI & 6.93 & 11.8 & 1.30 & -6.8 & -3.9 & 5.5 & 22.1 \\
$165 \mathrm{FMI}$ & 6.60 & 8.2 & 1.16 & -11.4 & -8.9 & 0.2 & 18.7 \\
\hline
\end{tabular}

According to the test, the comparison of crank angles corresponding to the cumulative combustion heat release $5 \%, 10 \%, 50 \%, 90 \%$ (CA05, CA10, CA50, CA90) is shown in Table 2. It can be seen that the starting point of combustion (CA05) of the micro internal combustion engine is relatively late, $5 \sim 8^{\circ} \mathrm{CA}$ later than the conventional size models. Due to the lower combustion heat release rate, the combustion duration was obviously prolonged, the rapid burning period (CA10 to CA90) extends about 20 ${ }^{\circ} \mathrm{CA}$ compared with the conventional models. Among them, the early stage of rapid combustion (CA10 to CA50) extends by $8 \sim 10^{\circ} \mathrm{CA}$; the late stage of rapid combustion (CA50 to CA90) extends by $10 \sim 13{ }^{\circ} \mathrm{CA}$.

The main reason for the low rate of combustion heat release of the micro internal combustion engine is that the combustion is not enough. Because of the small scale of the micro internal combustion engine, its fuel residence time is short. The fuel is exhausted without complete combustion at high speed. In addition, the large surface-volume ratio makes it large ratio of heat dissipation loss relative to combustion heat release, and it is also not conducive to fuel combustion in the cylinder.

Usually, compared with the platinum wire incandescent ignition combustion mode, the homogeneous charge compression ignition mode has the characteristics of longer ignition delay period, faster combustion rate in the main combustion period, shorter combustion duration and higher pressure rise rate [14-15]. Therefore, if we can shorten the ignition delay period to achieve the homogeneous charge compression ignition mode in the micro piston internal combustion engine, the above problems of the platinum wire incandescent ignition combustion mode can be solved.

\section{TEST ON COMBUSTION CHARACTERISTICS OF THE HOMOGENEOUS CHARGE COMPRESSION IGNITION MODE}

\subsection{Realization of the Homogeneous Charge Compression Ignition Mode}

For the reason of it is difficult to achieve compression combustion in the cold start-up state of the micro-combustion engine, we first put forward the idea: to achieve the homogenous compression combustion of the micro-piston internal combustion engine by increasing the compression ratio [16]. Four cylinders heads with different compression ratios are designed. And the compression ratio 
is $8,12,16$ and 20 respectively, as shown in figure 3 . The compression ratio of the micro piston type internal combustion engine is changed by adjusting the depth of the electric plug. All the combustion chamber is a flat-top structure. However, it is found that under normal temperature, even if the cylinder head with a compression ratio of 20 is used, the compression ignition cannot be realized.

An important reason why it is difficult to achieve combustion under cold start state is that the fuel has a high ignition temperature, and the compression of the micro-combustion engine does not provide sufficient temperature conditions. In view of this, we put forward the idea: make the homogenous compression combustion come true by raising the temperature of the cylinder and the platinum wire appropriately.

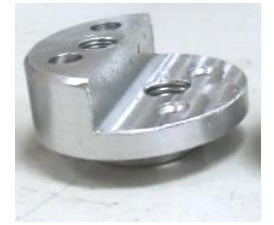

Compression ratio8

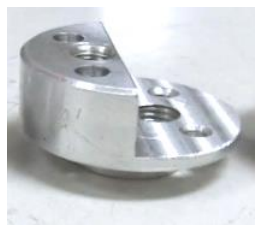

Compression ratio16

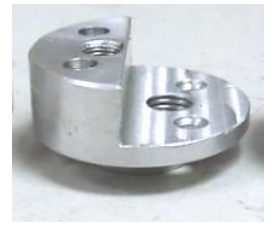

Compression ratio12

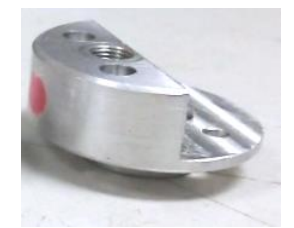

Compression ratio20

Fig.3 Cylinder heads with different compression ratio

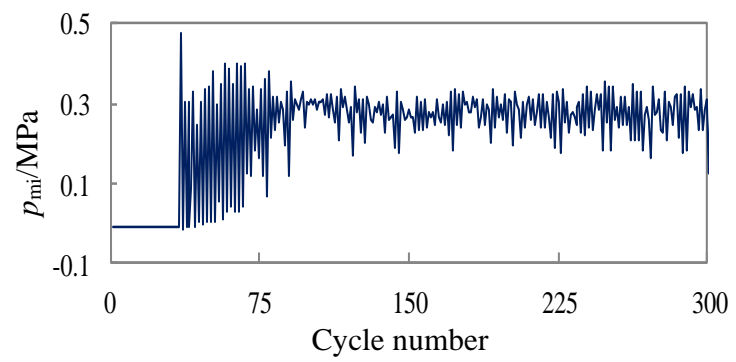

Fig.4 Experiment of compression ignition combustion

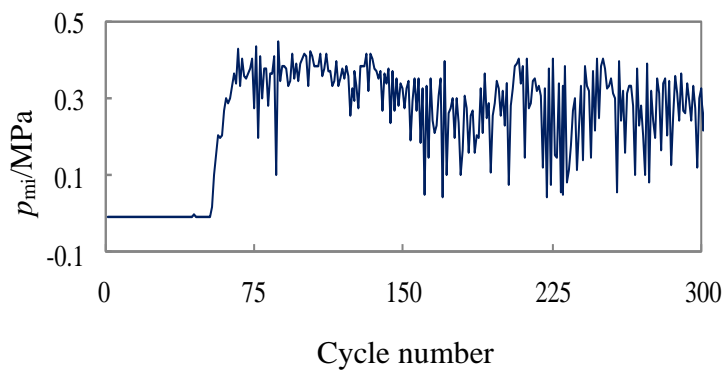

Fig.5 Experiment of platinum wire glow ignition combustion

The test is designed as follows: the micro piston internal combustion engine runs in the platinum wire incandescent ignition combustion mode for a period of time firstly, with a speed of $6000 \mathrm{r} / \mathrm{min}$. When the cylinder body reaches a certain temperature, shut off the throttle and make the engine flameout. During this process, the motor speed is kept at $6000 \mathrm{r} / \mathrm{min}$, that is, the micro piston internal combustion engine is under motored condition. After the temperature of platinum wire is reduced, the throttle is reopened, and the cylinder pressure is collected synchronously to test whether it can achieve the homogeneous charge compression ignition.

Figure 4 is the change curve of the mean indicated pressure (pmi) of the micro piston internal combustion engine. It can be seen that in the thirty-fifth cycle, that is, when the throttle is opened, its pmi value is changed from 0 of the previous cycle to $0.48 \mathrm{MPa}$, indicating that the engine realized combustion in this cycle.

In order to judge the combustion mode of the first combustion cycle in figure 4 , the combustion pressure of a single cycle is diagnosed and compared with that of the ignition mode. Figure 5 is the in-cylinder pressure of the ignition process after the platinum wire is electrified. It is shown in the figure that from the fifty-fourth cycle, the pmi value increases gradually from 0 , that is, the mixed gas in cylinder is ignited by the hot platinum wire.

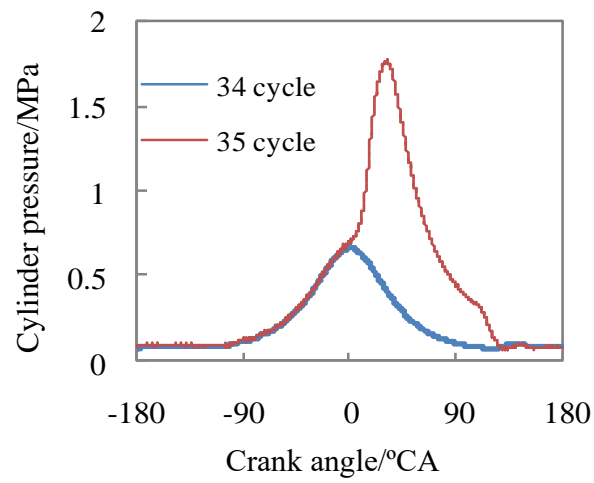

(a) HCCI

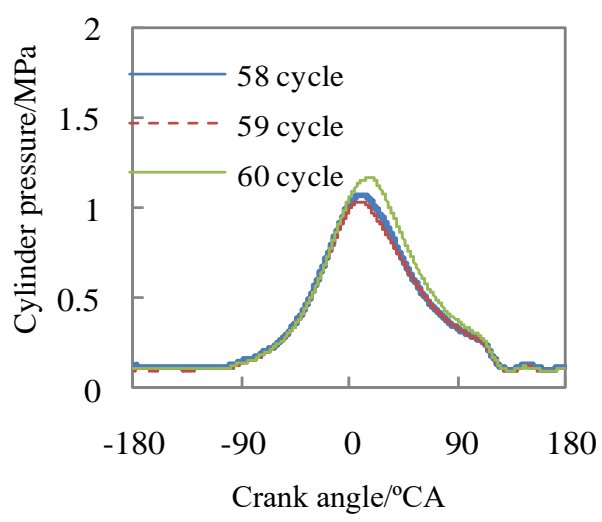

(b) Glow ignition of platinum wire

Fig. 6 combustion mode diagnosis

Figure 6 is a comparison of the combustion modes. Figure 6a is a comparison of the combustion pressure of the first combustion cycle (thirty-fifth cycle) and the previous cycle (thirty-fourth cycle). Figure $6 \mathrm{~b}$ is a combustion pressure comparison of 3 consecutive ignition cycles under the platinum wire incandescent ignition combustion mode, in which, the combustion pressure of the fifty-eighth, fifty-ninth, sixtieth cycle is selected for comparison. It can be seen from the figure that the maximum combustion pressure pmax is significantly higher than that of the platinum wire ignition mode in the first combustion cycle. It can be seen that the combustion of the cycle conforms to the homogenous compression combustion characteristics. 
Therefore, this cycle is considered to be the homogeneous charge compression ignition.

In figure 4, the first combustion cycle (thirty-fifth cycle) has the highest pmi value in the 300 test cycles. It is considered that the subsequent cycle is the platinum wire ignition mode, which does not belong to the homogeneous charge compression ignition mode. This is because under the high temperature of the platinum wire, the mixed gas will be directly ignited by the hot platinum wire.

The reason why the homogeneous charge compression ignition mode of the first cycle can be achieved is that the higher temperature of the cylinder block helps to combustion. In addition, although the temperature of the platinum wire is lower, it is not enough to ignite the mixed gas, it still has a certain temperature, which has a combustion-supporting effect.

\subsection{The Combustion Characteristics of the Homogeneous Charge Compression Ignition Mode}

In order to research the combustion characteristic of homogeneous charge compression ignition mode in micro piston type internal combustion engine, the combustion parameters of homogeneous charge compression ignition mode are tested under different temperatures. The selected temperatures are $90^{\circ} \mathrm{C} 、 140^{\circ} \mathrm{C}$ and $150^{\circ} \mathrm{C}$, and the test speed is $6000 \mathrm{r} / \mathrm{min}$.

Figure 7 shows the mean indicated pressure pmi change curve of the micro piston internal combustion engine under different temperature. As can be seen from the figure 7, the pmi value of the first combustion cycle is the maximum in the 300 cycles measured. It is suggested that the first combustion cycle in figure 7 is the homogeneous charge compression ignition.

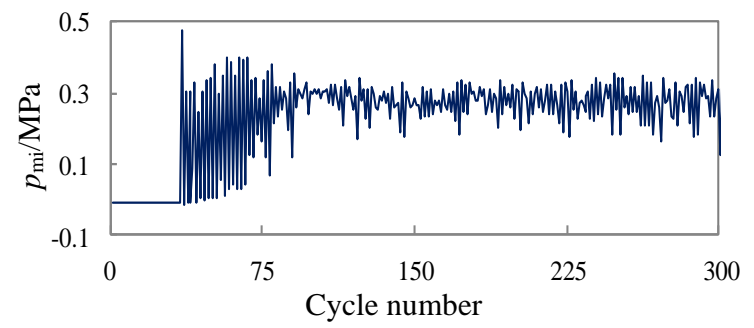

(a) $90^{\circ} \mathrm{C}$

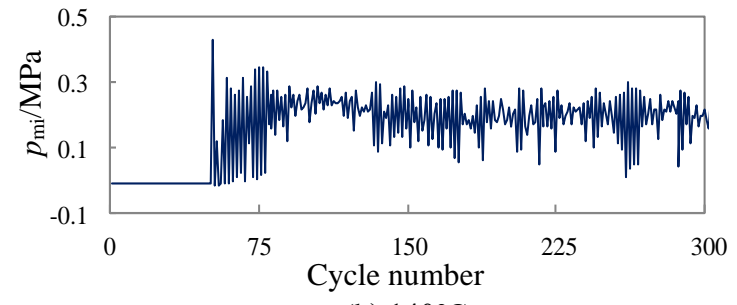

(b) $140^{\circ} \mathrm{C}$

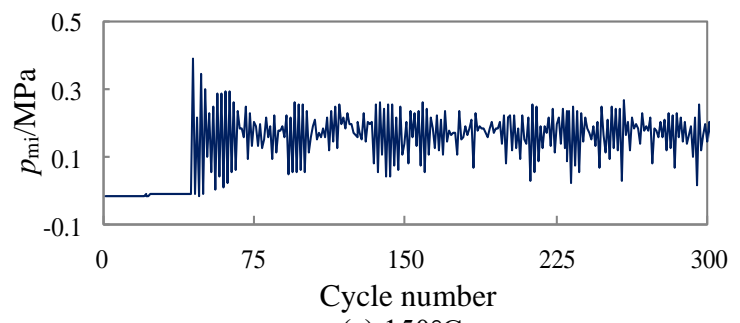

(c) $150^{\circ} \mathrm{C}$

Fig.7 Experiment of compression ignition combustion at different temperatures
Figure 8 shows the comparison of the combustion pressure and the instantaneous heat release rate between the homogeneous charge compression ignition mode and the platinum wire ignition mode. In the figure, I-90 represents the platinum wire ignition under the temperature of $90{ }^{\circ} \mathrm{C}$, $\mathrm{H}-90$ represents the homogeneous charge compression ignition under the temperature of $90^{\circ} \mathrm{C}$.

It can be seen from the figure that compared with the platinum wire incandescent ignition mode, when the mean compression ignition mode is adopted, the combustion heat release rate is greatly increased, the maximum combustion heat release rate is significantly increased, and the corresponding combustion duration is significantly shortened. The maximum heat release rate in the ignition mode is only about $2 \% /{ }^{\circ} \mathrm{CA}$, while in the homogeneous charge compression ignition mode, the maximum combustion heat release rate reaches $4.4 \% /{ }^{\circ} \mathrm{CA}$ at $90{ }^{\circ} \mathrm{C}$, and the improvement is more than doubled. So, the homogeneous charge compression ignition is an ideal combustion mode for micro piston type internal combustion engine, which contributes to improve its combustion characteristics. In addition, the heat release time of the homogeneous charge compression ignition cycle is relatively late, but as the temperature rises, there is an advance trend in the heat release time of the homogeneous charge compression ignition.

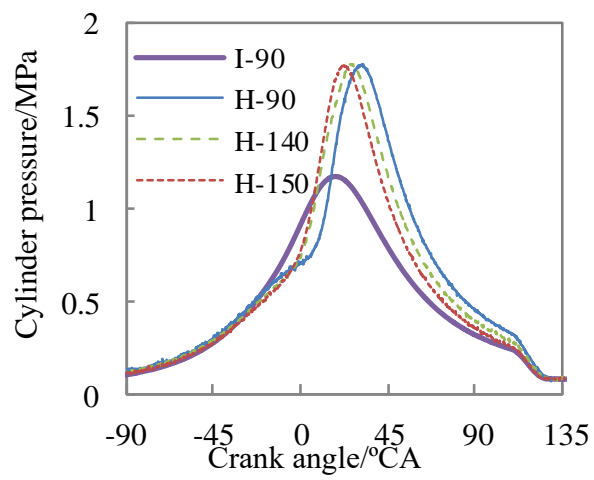

(a) Cylinder pressure

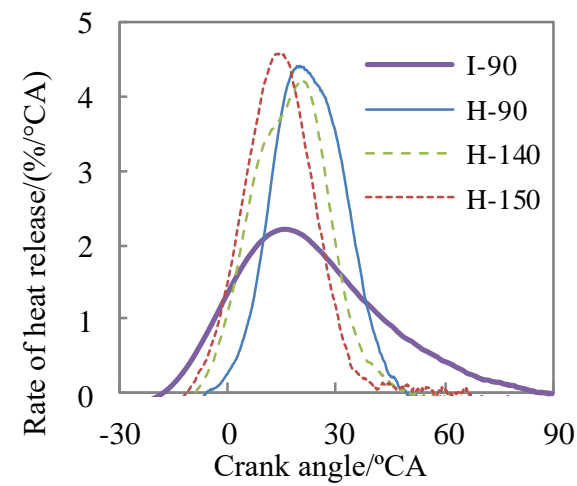

(b) Rate of heat release

Fig.8 Comparison of cylinder pressure and rate of heat release at different combustion modes

Figure 9 shows the comparison of combustion parameters such as the starting point of combustion and combustion duration between the homogeneous charge compression ignition and platinum wire incandescent ignition under different temperature. It can be seen from the figure that the CA05 of the homogeneous charge compression ignition cycle lags behind the corresponding ignition mode, and they are all located after top dead center 


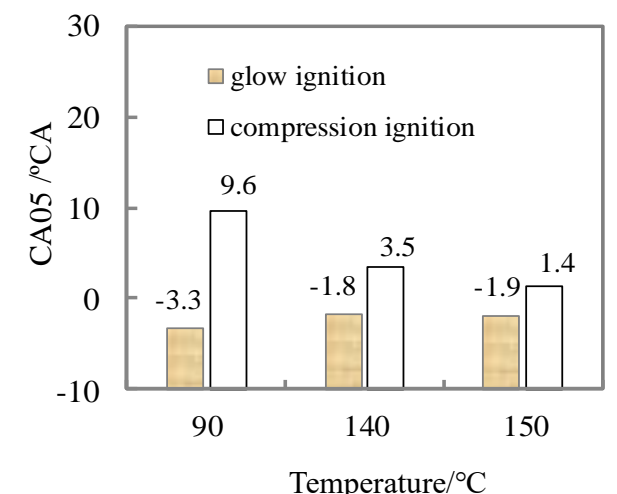

(a) $\mathrm{CA} 05$

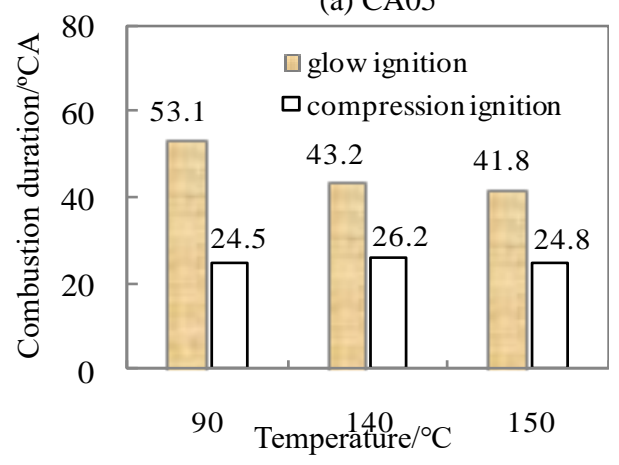

(b) Combustion duration

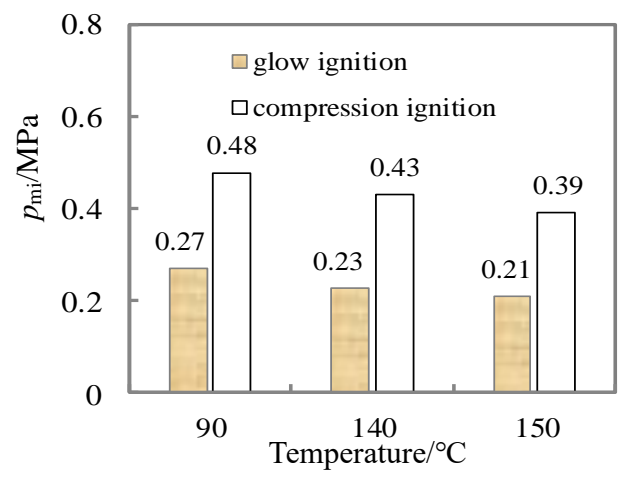

(c) mean indicated pressure

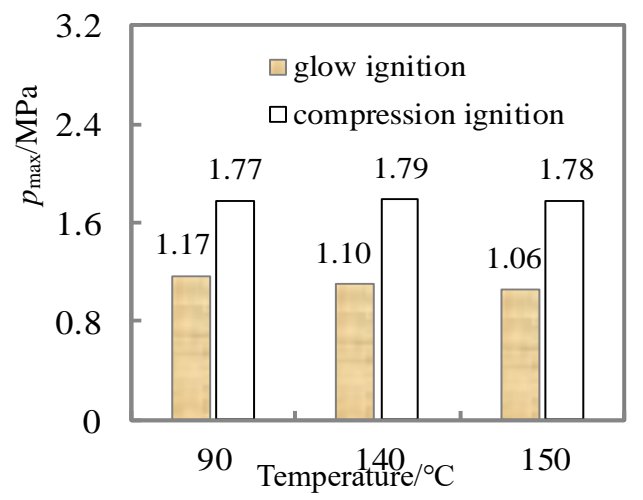

(d) The maximum pressure

Fig. 9. Comparison of combustion parameter at different combustion modes

and gradually advance as the temperature increases. After the homogeneous charge compression ignition mode is adopted, the combustion duration is substantially shortened, which facilitates the improvement of thermal efficiency.
For example, when the test temperature is $90^{\circ} \mathrm{C}$, the combustion duration is shortened from $53.1^{\circ} \mathrm{C}$ to $24.5^{\circ} \mathrm{C}$ and shortened by $28.6^{\circ} \mathrm{C}$.

It can also be seen from the figure that the $p_{\text {mi }}$ is greatly increased when the homogeneous charge compression ignition mode is adopted and the dynamic performance is significantly improved. When the test temperature is $90^{\circ} \mathrm{C}$, the $p_{\text {mi }}$ in homogeneous charge compression ignition mode reaches $0.48 \mathrm{MPa}$, which is a $76 \%$ increase compared to $0.27 \mathrm{MPa}$ in the platinum wire ignition mode. When the test temperatures are $140{ }^{\circ} \mathrm{C}$ and $150{ }^{\circ} \mathrm{C}$, there are also such obvious results, the increase rate is more than $80 \%$.

With the above analysis, it can be found that the micro-combustion engine can achieve homogenous compression combustion under a certain condition, and the combustion characteristics of the micro-internal combustion engine in compressed combustion mode is greatly improved.

So, a novel hybrid combustion mode, in-cylinder compression combustion supported by the platinum wire incandescent ignition, is put forward through the way of adjusting the temperature of platinum wire, and this novel combustion mode is considered as an ideal combustion mode of a miniature reciprocating piston internal combustion engine. In addition, it is also a potential approach to explore a fuel with the low ignition point and fast combustion flame speed to realize the homogeneous charge compression ignition mode in micro space.

\section{CONCLUSION}

1) The combustion characteristics of the platinum wire incandescent ignition combustion mod in the micro piston internal combustion engine are poor, the heat release rate is low, the combustion duration is long, and the combustion pressure is very low. The combustion duration is prolonged by about $20{ }^{\circ} \mathrm{CA}$ compared with conventional-size engines, the mean indicated pressure pmi is about $20 \%$ compared with the conventional-size engines.

2) The compression combustion cannot be achieved in the cold start-up state of the micro-combustion engine, and the compression combustion in the first cycle was realized by the way of increasing the temperature of the cylinder block and platinum wire appropriately

3) The combustion characteristics of the homogeneous charge compression ignition mode of the micro piston internal combustion engine are obviously better than the platinum wire incandescent ignition mode. The maximum heat release rate is obviously improved and the combustion duration is shortened by $28.6^{\circ} \mathrm{CA}$, and pmi is increased by $76 \%$. So, a novel hybrid combustion mode, in-cylinder compression combustion supported by the platinum wire incandescent ignition, is proposed and regarded as an ideal combustion mode of a miniature reciprocating piston internal combustion engine.

\section{ACKNOWLEDGMENTS}

The authors Acknowledgment the National Natural Science Foundation of China through grant 51175530, the Foundation and Advanced Research Program General Project of Chongqing City, China through grant cstc2016jcyjA0499 and the Board of Education Science and Technology Research Project of Chongqing City, China (Grant No. KJ1705112) for support of this work. 


\section{DECLARATION OF CONFLICTING INTERESTS}

The author(s) declared no potential conflicts of interest with respect to the research, authorship, and/or publication of this article.

\section{REFERENCE}

1. Chou SK, Yang WM, Chua KJ, et al. Development of micro power generators-A review. Applied Energy. 2011;88(1):1-16. https://doi.org/10.1016/j.apenergy.2010.07.010

2. Zhang L, Tang GZ, Liao ZB, et al. Development and experimental research on circumferential impulse microturbine power generation system. Proceedings of the Institution of Mechanical Engineers, Part C: Journal of Mechanical Engineering Science. 2014; 228(2): 378-387. https://doi.org/10.1177/0954406213484874

3. Yang WM, Chou SK, Li J. Microthermophotovoltaic power generator with high power density. Applied Thermal Engineering. 2009; 29(14/15): 3144-3148. https://doi.org/10.1016/j.applthermaleng.2009.04.015

4. Wang Y, Zhou ZJ, Zhou JH, et al. Micro newcomen steam engine using two-phase working fluid. Energy. 2011;36(2):917-921. https://doi.org/10.1016/j.energy.2010.12.019

5. Guo ZP, Wang YF, Zhang HJ, et al. Transient dynamics analysis of micro free piston swing engine. Chinese Internal Combustion Engine Engineering. 2014; 35(2): 119-124.

6. Cadou C, Menon S, Moulton N. Performance measurement and scaling in small internal combustion engines. 41st AIAA Aerospace Sciences Meeting and Exhibit, Reno, AIAA 2003-0671, Reno NV, 2003.

7. Sher E, Sher I. Theoretical limits of scaling-down internal combustion engines. Chemical Engineering Science. 2011; 66(3): 260-267. https://doi.org/10.1016/j.ces.2010.10.005

8. Vijayan V, Gupta AK. Flame dynamics of a meso-scale heat recirculating combustor. Applied Energy. 2010; 87(12): 3718-3728. https://doi.org/10.1016/j.apenergy.2010.06.003

9. Cho JH, Lin CS, Richards CD, et al. Demonstration of an external combustion micro-heat engine. Proceedings of the Combustion Institute. 2009; 32(2): 3099-3105.

10. Menon S, Moulton N, Cadou C. Development of a dynamometer for measuring small internal-combustion engine performance. Journal of Propulsion and Power, 2007; 23(1): 194-201.

11. Menon S, Cadou PC. Scaling of miniature piston-engine performance, Part 1: Overall Engine Performance. Journal of Propulsion and Power. 2013; 29(4): 774-787. https://doi.org/10.2514/1.B34638

12. Shirsat V, Gupta AK. A review of progress in heat recirculating meso-scale combustors. Applied Energy. 2011; 88(12): 4294-4309. https://doi.org/10.1016/j.apenergy.2011.07.021

13. David CW, Jeongmin A. Advances and challenges in the development of power-generation systems at small scales. Progress in Energy and Combustion Science. 2011; 37(5):583-610.

https://doi.org/10.1016/j.pecs.2010.12.002

14. Lei Tian. Experimental Tests and Simulations of A 1.5 cc Miniature Glow-Ignition Two-Stroke Engine. SAE International, paper number: 2010-32-0018:0148-7191.

15. Mohsen Pourfallah, Mahbod Armin. An experimental and numerical study of the effects of reformer gas (H2 and $\mathrm{CO}$ ) enrichment on the natural gas homogeneous charge compression ignition (HCCI) engine. Heat and Mass Transfer. 2019; 55(7): 1947-1957. https://doi.org/10.1007/s00231-018-2479-z

16. Qian Wang, Liming Dai, Kai Wu, Jin Bai, Zhixia He. Study on the combustion process and work capacity of a micro free-piston engine. Journal of Mechanical Science and Technology. 2015; 29(11): 4993-5000. https://doi.org/10.1007/s12206-015-1047-4

17. Anand Lalwani, Swapnil Awate, Arindrajit Chowdhury, Sheshadri Sreedhara. Conversion of a single-cylinder internal combustion engine to dual-mode homogeneous charge compression ignition engine. Clean Technologies and Environmental Policy. 2019; 21(1): 23-37. https://doi.org/10.1007/s10098-018-1613-4

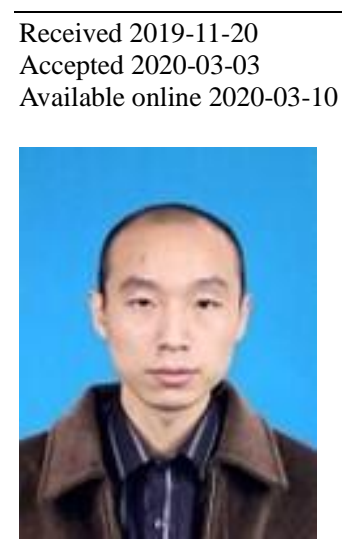

Tang Gang ZHI received his B.S. degree from Chongqing University, China, in 2003, and got the $\mathrm{PhD}$ in Automotive Engineering from the State Key Lab of Mechanical Transmission, Chongqing University, China, in 2014. He is currently an assistant professor at School of Mechatronics \& Automotive Engineering, Chongqing Jiaotong University, China. He is focused on development of micro power energy system and diagnostic of novel engines. 